\title{
HEAD AND NECK
}

\section{IFN- $\gamma$ and other serum cytokines in head and neck squamous cell carcinomas}

\author{
IFN- $\gamma$ e altre citochine sieriche nei carcinomi squamocellulari della testa \\ e del collo
}

\author{
F. BUSSU1, ${ }^{1}$, C. GRAZIANI ${ }^{12}$, R. GALLUS ${ }^{1}$, A. CITTADINI ${ }^{2}$, J. GALLI ${ }^{1}$, E. DE CORSO ${ }^{1}$, G. DI CINTIO ${ }^{1}, M^{2}$. CORBI $^{2}$, \\ G. ALMADORI ${ }^{1}$, A. BONINSEGNA ${ }^{2}$, G. PALUDETTI ${ }^{1}$, A. SGAMBATO $^{2}$ \\ ${ }^{1}$ Department of Otolaryngology, ${ }^{2}$ Department of General Pathology, Università Cattolica del S. Cuore, Policlinico \\ Agostino Gemelli, Rome, Italy; ${ }^{3}$ ENT Division, Azienda Ospedaliero Universitaria di Sassari, Italy
}

\section{SUMMARY}

\begin{abstract}
Altered immune responses have been reported in head and neck cancer, and some of these responses have been associated with poor clinical outcomes. A multiple-array technology platform was used to simultaneously evaluate the levels of 25 cytokines. Pre-treatment serum levels were evaluated in 31 HNSCC patients and 6 healthy controls. The levels of 8 cytokines, specifically IL-1ra, IL-2, IL-5, IL-6, IL-8, IL-17, IFN- $\gamma$ and IP-10, were significantly higher in patients than in controls. Among cancer patients we observed lower levels of IFN- $\gamma$ and IL-7 in cases with nodal metastases compared to those with cNO disease. We observed increases in the levels of some serum cytokines in HNSCC patients, as well as reductions in selected cytokines associated with regional progression. These findings provide an intriguing perspective on the development and validation of novel markers for follow-up evaluations and predictions of regional spreading in HNSCC patients.
\end{abstract}

KEY WORDS: Head and neck SCC • Nodal metastasis $\bullet$ Predictive factors $\bullet$ Cytokines $\bullet$ Inflammation $\bullet$ IFN- $\gamma$

\section{RIASSUNTO}

$\grave{E}$ noto che nelle neoplasie della testa e del collo vi siano delle alterazioni della risposta immune, ed alcune di tali alterazioni sono state associate ad un peggioramento prognostico. Abbiamo utilizzato una piattaforma con una tecnologia multi-array per valutare simultaneamente $i$ valori di 25 citochine nel siero di 31 pazienti, affetti da carcinomi squamosi della testa e del collo prima del trattamento, e di 6 controlli sani. I livelli di 8 citochine, IL-1ra, IL-2, IL-5, IL-6, IL-8, IL-17, IFN- $\gamma$ ed IP-10, sono risultati significativamente più elevati nei pazienti che nei controlli. Tra i pazienti i casi con metastasi linfonodali mostravano livelli significativamentre inferiori di IFN- $\gamma$ ed IL-7 rispetto ai casi cNO. Pertanto alcune citochine tendono ad essere più elevate nei soggetti affetti da carcinomi squamocellulari della testa e del collo, ma nel contesto di tale gruppo di pazienti si osserva un calo specifico di alcune citochine in caso di metastasi linfonodali. Tali dati aprono prospettive interessanti soprattutto ai fini di una miglior definizione del rischio di metastasi/recidive linfonodali con implicazioni sia in termini di impostazione terapeutica che di follow up.

PAROLE CHIAVE: Carcinomi squamosi della testa e collo $\bullet$ Metastasi linfonodali $\bullet$ Fattori predittivi $\bullet$ Citochine $\bullet$ Infiammazione $\bullet$ Interferongamma

Acta Otorhinolaryngol Ital 2018;38:94-102

\section{Introduction}

Head and neck squamous cell carcinoma (HNSCC) represents approximately $3 \%$ of all malignant tumours in the United States ${ }^{1}$ and Europe ${ }^{2}$, but is much more prevalent in other parts of the world ${ }^{3}$. The standard therapeutic approach, which includes surgery, irradiation and chemotherapy, either alone or in combination, has been somewhat modified over the last 30 years; however, the overall survival rate has not drastically improved ${ }^{13}$.
The persistently high rate of advanced lesions is among the potential reasons for the failure to improve the HNSCC survival rate. In general, screening attempts have been completely unsuccessful, such that for the larynx, the most frequently affected primary site in European patients ${ }^{4}$, where less than $1 \%$ of SCC patients are asymptomatic at presentation. The definition of high-risk groups that should be submitted to screening would likely increase this rate. Oncogenic viruses, particularly EpsteinBarr and high-risk papillomavirus, have been shown to 
play causative roles in subsets of nasopharyngeal ${ }^{5}$ and oropharyngeal ${ }^{6}$ cancers, respectively, and therefore might be a good starting point. Nevertheless, the most frequent site of origin for HNSCC are the oral cavity and larynx, for which the main proven risk factors remain cigarette smoking and alcohol consumption ${ }^{3}$; however, these factors do not define a sufficiently restricted population to monitor for effective prevention and/or screening.

Another issue in head and neck oncology is that the prognostic stratification is inadequate because patients who are affected by tumours with similar clinicopathological parameters and are undergoing the same treatment can differ widely in their prognoses. This is likely due to the extreme biological heterogeneity of HNSCCs, and contributes to the known controversies concerning therapeutic algorithms (on management of cN0 necks) ${ }^{7}$.

Many clinical and epidemiologic studies have suggested a strong association between inflammation, with its mediators, and cancer ${ }^{8-11}$, including cancers of the head and neck ${ }^{12-14}$.

In the present study, we investigated the serum concentrations of various cytokines in patients with laryngeal and oral SCC, and compared these with the concentrations in healthy subjects, to identify alterations in inflammatory pathways associated with carcinogenesis.

We tested a panel of 26 cytokines that are important in the inflammatory response and immune system regulation and associated with different immune pathways, giving specific information, and in particular concerning $\mathrm{Th} 2$ and Th1 immune responses.

Cytokine levels were also correlated with tumour characteristics (e.g., site of origin and $\mathrm{T}$ and $\mathrm{N}$ classification) and oncologic outcomes to identify parameters that might supplement TNM and other information currently available to clinicians to assess prognoses, treatment responses and clinical behaviours (e.g., tendency to regional metastasis) of HNSCC patients.

\section{Materials and methods}

\section{Patients}

From February 2010 to March 2012, we enrolled 31 patients ( 5 women, 26 men; age range, 32-82 years; mean, 57 years) who were affected by primary, previously untreated and biopsy proven SCC arising from oral cavity or larynx, as evaluated by the multidisciplinary head and neck tumour board of the Policlinico Agostino Gemelli, Università Cattolica del Sacro Cuore, Rome, Italy.

Staging according to the TNM AJCC classification $7^{\text {th }}$ edition, and treatment recommendation were defined, patients signed informed consent for their participation in the present study, which had been previously approved by the ethical committee.

The circulating levels of interleukin-1b (IL-1b), interleukin-1 receptor antagonist (IL-1Ra), IL-2, IL-4, IL-5, IL-6, IL-7, IL-8, IL-9, IL-10, IL-12, IL-13, IL-17, eotaxin, basic fibroblast growth factor (FGF-b), granulocyte colonystimulating factor (G-CSF), interferon-gamma (IFN- $\gamma$ ), IFN- $\gamma$-inducible protein 10 (IP-10), human monocyte chemoattractant protein 1 (HuMCP-1), macrophage inflammatory proteins-1-alpha and 1-beta (MIP-1 $\alpha$ and $1 \beta$ ), platelet-derived growth factor-BB (PDGF-BB), regulated upon activation, normal T-cell expressed secreted (RANTES), tumour necrosis factor-alpha (TNF- $\alpha$ ) and vascular endothelial growth factor (VEGF) were investigated in sera collected before primary treatment. All SCC originated from the oral cavity $(n=16)$ and larynx $(n=15)$, which are the most frequent sites of HNSCC ${ }^{1}$. All patients had a history of cigarette smoking.

Selection of primary treatment modality was always shared in the institutional multidisciplinary head and neck tumour board. All oral cavity cases were treated primarily by surgery. As for laryngeal SCCs, in our tumour board treatment choice is based mainly on $\mathrm{cT}$, and on the patient's general condition and preference. Namely, we primarily irradiated cT1 and cT2 and we recommended primary surgery in cT4 cases; cT3 cases were discussed in the tumour board and underwent surgery or radiotherapy depending on the patient's general conditions and feasibility of function preservation surgery (supracricoid operations). Among patients who underwent primarily radiochemotherapy, there were also cT4 patients who refused the recommended total laryngectomy and preferred to try to keep their larynx, after having been informed about the lower survival rates reported in literature. Postoperative radiation (mostly associated with cisplatin) was administered for $\mathrm{pN}$ 2-3 disease, extracapsular spread and adverse pathologic primary site features including pT4 disease, perineural invasion, involvement of surgical margins, or lymphovascular invasion.

The follow-up time was calculated from the treatment date (surgery or final session of chemo/radiotherapy). For controls, sera were collected from 6 healthy sex and age-matched volunteers who were current smokers with personal histories negative for malignancy, without recent trauma or surgery, and who were not pregnant. Personal data for cases and controls and clinical data for HNSCC patients are summarised in Table I. Peripheral venous blood was collected into Vacuette (Greiner bioone, Kremsmünster, Austria) tubes and was immediately centrifuged at $4{ }^{\circ} \mathrm{C}$ and $4000 \mathrm{rpm}$ for 5 minutes. Serum samples were collected and multiple aliquots were stored 
at $-80^{\circ} \mathrm{C}$ until analysis, at which time the serum concentrations of cytokines were determined in a multiplex cytokine analysis.

\section{Multiplex cytokine analysis}

A Luminex xMAP system (Bio-Plex 200 System, BioRad Laboratories, Hercules, CA, USA), which is a multiplex biometric enzyme-linked immunosorbent assay (ELISA)-based immunoassay that contains dyed microspheres conjugated to monoclonal antibodies specific for target proteins, was used according to the manufacturer's instructions. The cytokines evaluated in the panel (BioPlex Human Cytokine Assay; BioRad) were IL-1 $\beta$, IL1Ra, IL-2, IL-4, IL-5, IL-6, IL-7, CXCL8 (IL-8), IL-9, IL-10, IL-12 (p70), IL-13, IL-17, basic FGF, eotaxin, GCSF , IFN- $\gamma$, IP-10, MCP-1, MIP-1a and $\beta$, PDGF-BB, RANTESTNF- $\alpha$ and VEGF.

The serum samples were diluted 1:4 and incubated with antibody-coupled beads. The resulting complexes were washed and incubated first with a biotinylated detection antibody and then with streptavidin-phycoerythrin prior to assessing the cytokine concentration titres. Concentrated human recombinant cytokines were provided by the vendor (BioRad, Inc.). Broad ranges of standards (1.95$32,000 \mathrm{pg} / \mathrm{ml}$ ) were used to establish standard curves with which to maximise the sensitivity and dynamic range of the assay. Cytokine levels were determined on a Bio-Plex array reader, an automated flow-based microfluidics device that uses a dual-laser fluorescent detector with real-time digital signal processing for quantification. This instrument quantifies multiplex immunoassays in 96-well plates. The concentrations in $\mathrm{pg} / \mathrm{ml}$ were calculated from standard curves with software provided by the manufacturer. A regression analysis was performed to derive an equation that was then used to predict the concentrations of cytokines in the serum samples.

\section{Statistical analysis}

Statistical analysis was performed with JMP software, release 7.0.1 (SAS Institute). The level was fixed at 0.05 for all statistical tests. Correlations between nominal variables were evaluated with a $\mathrm{c}^{2}$ test. Differences in the concentrations of different cytokines between controls (c) and patients (p) and between the $\mathrm{cNO}$ and $\mathrm{cN}+$ cases were evaluated with a t-test. Differences among tumours that originated in the two sites (oral cavity vs. larynx), controls and among different the $\mathrm{cT}$ and $\mathrm{cN}$ classifications were evaluated by ANOVA variance analysis, and pairs were then compared with the Tukey-Kramer test. For a more thorough evaluation of the variations in serum cytokine levels along with increasing tumour staging, we trans-
Table I. Characteristics of patients in the entire series according to the primary treatment group.

\begin{tabular}{|c|c|c|c|c|}
\hline $\begin{array}{l}\text { Characteristic } \\
\text { Age }\end{array}$ & \multicolumn{2}{|c|}{ Patients $(n=31)$} & \multicolumn{2}{|c|}{ Controls $(n=6)$} \\
\hline $\begin{array}{l}\text { Median } \\
\text { Range }\end{array}$ & \multicolumn{2}{|c|}{$\begin{array}{c}63 \\
32-82\end{array}$} & \multicolumn{2}{|c|}{$\begin{array}{c}61 \\
47-72\end{array}$} \\
\hline \multicolumn{5}{|l|}{ Sex-no. (\%) } \\
\hline Male & 26 & (84\%) & 5 & $(83 \%)$ \\
\hline Female & 5 & $(16 \%)$ & 1 & $(17 \%)$ \\
\hline \multicolumn{5}{|l|}{ Smoking habits-no. (\%) } \\
\hline Less than 10 pack/years & 10 & $(32 \%)$ & 2 & $(33 \%)$ \\
\hline More than 10 pack/years & 21 & $(68 \%)$ & 4 & $(67 \%)$ \\
\hline \multicolumn{5}{|l|}{ Drinking habits-no. (\%) } \\
\hline Non drinker & 12 & $(39 \%)$ & 2 & $(33 \%)$ \\
\hline 1-4 glasses/day & 13 & $(42 \%)$ & 3 & $(50 \%)$ \\
\hline More than 4 glasses a day & 6 & $(19 \%)$ & 1 & $(17 \%)$ \\
\hline \multicolumn{5}{|l|}{ Follow up } \\
\hline $\begin{array}{l}\text { Median } \\
\text { Range }\end{array}$ & \multicolumn{2}{|c|}{$\begin{array}{c}8.3 \\
0.2-21\end{array}$} & & - \\
\hline \multicolumn{5}{|l|}{ Site of primary-no. (\%) } \\
\hline Oral cavity & 16 & $(52 \%)$ & \multicolumn{2}{|c|}{-} \\
\hline Larynx & 15 & $(48 \%)$ & \multicolumn{2}{|c|}{-} \\
\hline \multicolumn{5}{|l|}{ Primary treatment-no. (\%) } \\
\hline Surgery & 22 & $(71 \%)$ & \multicolumn{2}{|l|}{-} \\
\hline Radio \pm chemotherapy & 9 & $(21 \%)$ & \multicolumn{2}{|l|}{-} \\
\hline \multicolumn{5}{|l|}{ TNM staging-no. (\%) } \\
\hline । & 3 & $(10 \%)$ & \multicolumn{2}{|l|}{-} \\
\hline$\|$ & 9 & $(29 \%)$ & \multicolumn{2}{|l|}{-} \\
\hline III & 2 & $(6 \%)$ & \multicolumn{2}{|l|}{-} \\
\hline IVa & 17 & $(55 \%)$ & \multicolumn{2}{|l|}{-} \\
\hline \multicolumn{5}{|l|}{ T stage-no.(\%) } \\
\hline T1 & 4 & $(13 \%)$ & \multicolumn{2}{|l|}{-} \\
\hline T2 & 12 & $(39 \%)$ & \multicolumn{2}{|l|}{-} \\
\hline T3 & 3 & $(9 \%)$ & \multicolumn{2}{|l|}{-} \\
\hline T4a & 12 & $(39 \%)$ & \multicolumn{2}{|l|}{-} \\
\hline \multicolumn{5}{|l|}{ N stage-no.(\%) } \\
\hline NO & 17 & $(55 \%)$ & \multicolumn{2}{|l|}{-} \\
\hline N1 & 3 & $(10 \%)$ & - & \\
\hline $\mathrm{N} 2 \mathrm{a}$ & 2 & $(6 \%)$ & - & \\
\hline $\mathrm{N} 2 \mathrm{~b}$ & 4 & $(13 \%)$ & - & \\
\hline N2C & 5 & $(16 \%)$ & - & \\
\hline
\end{tabular}

formed the nominal $\mathrm{cT}$ and $\mathrm{cN}$ parameters to numerical variables (numeric $\mathrm{T}$ and $\mathrm{N}$ scores; $\mathrm{cT} 4 \mathrm{a}=4, \mathrm{cT} 4 \mathrm{~b}=5$, $\mathrm{cN} 2 \mathrm{a}=2, \mathrm{cN} 2 \mathrm{~b}=3, \mathrm{cN} 2 \mathrm{c}=4, \mathrm{cN} 3=5$ ) and sought $\mathrm{a}$ linear fit by analysis of variance. The impact of different parameters on survival were evaluated by a Cox regres- 
Table II. Mean values of cytokines in controls and cases (statistically significant differences are indicated with *).

\begin{tabular}{|c|c|c|}
\hline Cytokine & Value in controls (mean \pm SD) & Value in cases (mean \pm SD) \\
\hline$\| \mathrm{L}-1 \mathrm{~b}$ & $3.3133333 \pm 0.8841418$ & $3.674 \pm 0.8323154$ \\
\hline IL-1ra* & $174.90667 \pm 17.770011$ & $237.06833 \pm 75.716824$ \\
\hline$\| \mathrm{L}-2^{*}$ & $1.715 \pm 2.9156251$ & $8.0387097 \pm 7.2977836$ \\
\hline $\mathrm{IL}-4$ & $9.425 \pm 2.0147332$ & $11.432258 \pm 2.3363158$ \\
\hline $1 \mathrm{~L}-5^{\star}$ & $3.4616667 \pm 0.412864$ & $4.4770968 \pm 1.8866005$ \\
\hline$\| \mathrm{L}-6^{*}$ & $9.1083333 \pm 1.1434232$ & $14.095806 \pm 4.3274864$ \\
\hline IL-7 & $13.881667 \pm 2.6957776$ & $16.143548 \pm 4.848343$ \\
\hline$\| \mathrm{L}-8^{*}$ & $32.186667 \pm 5.5094489$ & $40.000323 \pm 10.059768$ \\
\hline$\| L-9$ & $33.548333 \pm 18.8509$ & $46.597097 \pm 25.720585$ \\
\hline IL-10 & $30.395 \pm 33.645025$ & $22.915161 \pm 12.610672$ \\
\hline$\| \mathrm{L}-12$ & $95.153333 \pm 37.067161$ & $132.97935 \pm 84.327459$ \\
\hline$\| \mathrm{L}-13$ & $12.19512,195 \pm 3.6285024$ & $14.570645 \pm 5.7731684$ \\
\hline$\| \mathrm{L}-17^{*}$ & $190.29667 \pm 61.275395$ & $253.8671 \pm 67.58494$ \\
\hline Eotaxin & $233.67167 \pm 97.855583$ & $243.08645 \pm 112.18061$ \\
\hline FGF-basic & $47.305 \pm 23.345764$ & $55.560645 \pm 27.172748$ \\
\hline G-CSF & $72.231667 \pm 18.809514$ & $75.645161 \pm 16.2412$ \\
\hline IFN-g* & $311.015 \pm 51.866943$ & $376.45903 \pm 75.010629$ \\
\hline $\mathbb{I P}-10^{*}$ & $1488.3367 \pm 510.41972$ & $2502.8471 \pm 1098.5081$ \\
\hline Hu MCP-1(MCAF) & $60.086667 \pm 21.832594$ & $45.274839 \pm 16.429516$ \\
\hline Hu MIP-1a & $8.8483333 \pm 2.2179217$ & $9.0803226 \pm 2.1559568$ \\
\hline PDGF-bb & $14614.73 \pm 5313.271$ & $17966.356 \pm 4937.8699$ \\
\hline MIP-1b & $113.71333 \pm 34.277828$ & $118.45355 \pm 30.917572$ \\
\hline RANTES & $9447.305 \pm 850.45661$ & $9032.6235 \pm 1481.9593$ \\
\hline TNF-alpha & $39.131667 \pm 7.2147$ & $43.99129 \pm 11.821503$ \\
\hline VEGF & $132.37667 \pm 65.794253$ & $203.30032 \pm 175.79658$ \\
\hline
\end{tabular}

sion analysis (only univariate because of the low numbers of cases and recorded events).

\section{Results}

Statistically significant differences between controls and patients with regard to concentrations of the different cytokines are reported in Table II and schematically represented by box plots in Figure 1. The statistically significant differences observed among the two different tumour sites and controls are shown in Figure 2. Two cytokines were significantly overexpressed only in patients with specific SCC subsites, namely IL-6 in laryngeal SCC patients and IP-10 in oral cavity SCC patients.

We found no significant differences or correlations between the levels of various cytokines and the T classification, although a trend $(\mathrm{p}=0.0615$ in the variance analysis) towards a positive correlation between the IP-10 levels and numeric $\mathrm{T}$ scores was observed.

However, when we evaluated the association between cytokine levels and the $\mathrm{N}$ classification, a significant cor- relation of lower levels of some with nodal involvement (IL-7, FGF-basic, IFN- $\gamma$, HuMIP-1a, see figure 3 on the right) and with the numeric $\mathrm{N}$ score were seen (IL-7, eotaxin, IFN- $\gamma$, see Figure 3 on the left).

In Cox univariate survival analysis, we observed that higher IFN- $\gamma(p=0.0218)$ and lower IL-1ra $(p=0.0376)$ levels were associated with longer disease-specific survival.

\section{Discussion}

We observed increases in the levels of several cytokines in sera from HNSCC patients compared to sera from controls. This observation confirms the well-known link between inflammation and cancer that has already been observed in head-and-neck oncology. This observation could be linked to the presence of the tumour and its interactions with the host ${ }^{815-18}$, or could indicate an immunological predisposition to cancer development ${ }^{81115}$. In the former scenario, inflammatory mediators should be evaluated as tumour markers that could be employed in 

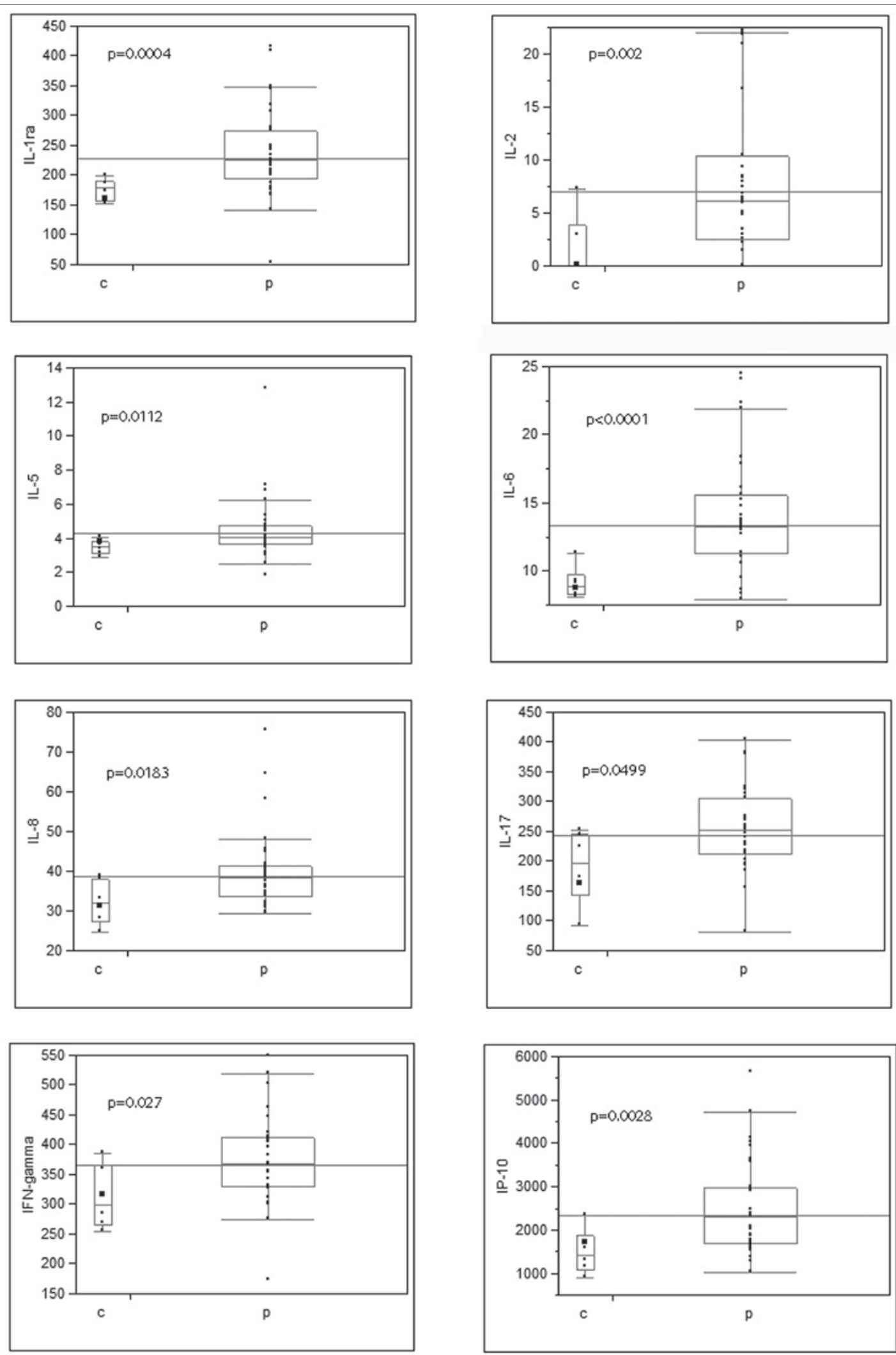

Fig. 1. Box plots of 8 cytokines (for which the levels were significantly higher in sera from patients (p), compared to controls (c). P-values were obtained with a two-sided t-test. 

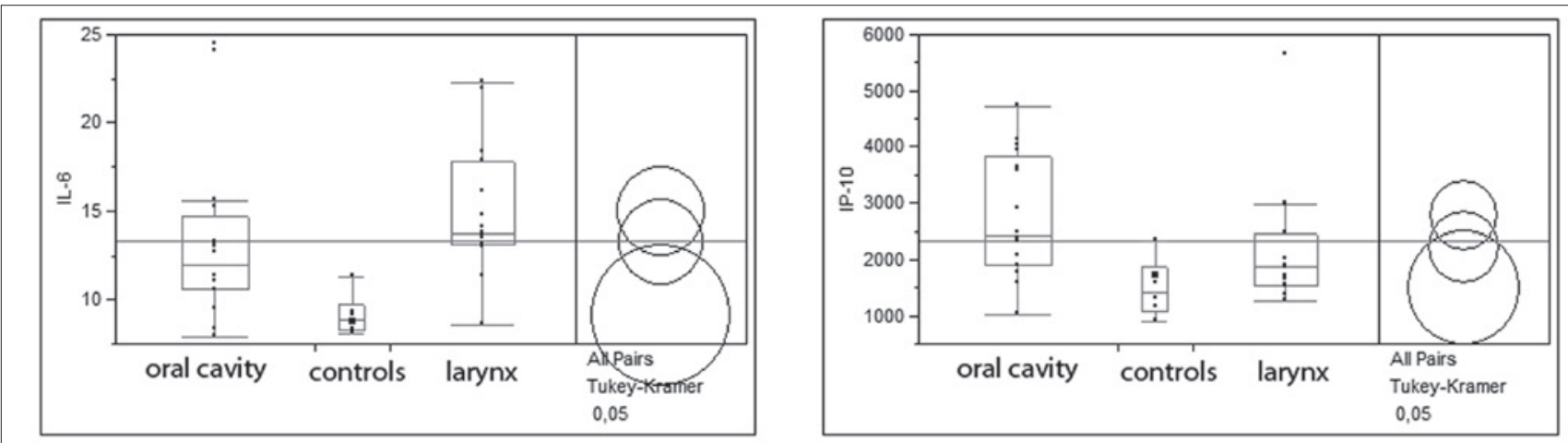

Fig. 2. When compared with controls, IL-6 serum levels were significantly higher in laryngeal but not in oral SCC patients; IP-10 levels were significantly higher only in oral SCC patients.

follow-up for early detection of recurrence; in the latter, certain immunological conditions might be risk factors for development of malignancy and could be taken into account when selecting subjects for screening.

Likely, both of these scenarios are true, and in our series, it was difficult to discriminate between the alterations that preceded and those that derived from cancer progression. In our patients, the cytokines with the most significant increases were IL-6 and IL-1Ra. Increased IL-6 levels have already been associated with HNSCC ${ }^{19-21}$, as well as with IL-8 ${ }^{12}{ }^{22}$, another upregulated cytokine among our patients. IL- 6 might contribute to cancer progression through STAT-3-mediated paracrine or autocrine proliferative stimulation and through additional inhibitory effects on anti-tumour Th1 immune responses ${ }^{23}{ }^{24}$. Nevertheless, in contrast to previous studies, in the present series, we failed to demonstrate any correlation between IL-6 itself and the disease stage ${ }^{25}$ or prognosis ${ }^{19}$, although the limited number of patients and the short follow-up period might explain this result. Actually, in the present series, IL-6 was significantly increased only in laryngeal SCC patients, and the reasons for this observation remain to be clarified. We instead observed a correlation between increased levels of IL1-Ra and worse prognosis. IL1-Ra levels have been correlated with prognosis in Hodgkin lymphoma ${ }^{26}$ and have been shown to be elevated in head and neck SCC tissues ${ }^{27}$. IP-10 and its corresponding receptor CXCR3 have been shown to be involved in carcinogenesis ${ }^{28}$ including malignant melanoma ${ }^{29}$, ovarian carcinoma ${ }^{30}$, multiple myeloma ${ }^{31}$, B-cell lymphoma ${ }^{32}$ and basal cell carcinoma ${ }^{33}$. In our series, the increased levels of IP-10 in patients with oral SCC, which are usually bulkier than laryngeal SCC, and in those with higher $\mathrm{T}$ scores (even if not significant), could suggest that IP-10 levels are influenced by tumour volume.
The prognostic role of IL-1Ra deserves in-depth evaluation in larger perspective studies. Nevertheless, these results provide a perspective for the use of some cytokines as tumour markers in clinical practice, such as during follow-up of HNSCC patients, also on account of the clear lack of reliable serum follow-up markers, of which the SCC antigen is the most used, despite its known issues regarding sensitivity and specificity ${ }^{34}$.

Immune responses in head and neck SCC patients are reportedly unbalanced towards the secretion of Th2 cytokines, which would prevent effective antitumour Th1 immune responses ${ }^{35}$. In the present study, we observed the upregulation of both Th1 (IFN- $\gamma$, IL-2 and IP-10) and Th2 (IL-4, IL-6 and IL-10) cytokines in HNSCC patients compared to healthy subjects, and the above-cited imbalance become evident only with regional progression, which is, however, the main clinical factor that affects survival in these patients. In fact, IFN- $\gamma$, which is among the most important Th1 pathway cytokines, was clearly downregulated in cases with nodal involvement and such downregulation displayed a linear correlation with regional progression. IFN- $\gamma$ was also the only serum cytokine that displayed a protective effect when evaluated relative to prognosis; its crucial role in HNSCC has already been described at both a molecular ${ }^{36}$ and clinical level ${ }^{22}$. In addition to IFN- $\gamma$, other cytokines that did not have specific Th1 activity were significantly downregulated in cases with nodal involvement and/or showed linear correlations with numeric $\mathrm{N}$ scores in our series, and none of these differed significantly between the cases and controls (except IFN- $\gamma$ ). Among these downregulated cytokines, IL-7 was recently found to perform a relevant antitumour activity by inducing the expansion of tumour-specific CD4+ T cell effectors more efficiently than IL-2 ${ }^{37}$. The serum eotaxin levels undergo significant modifications after the induc- 
A
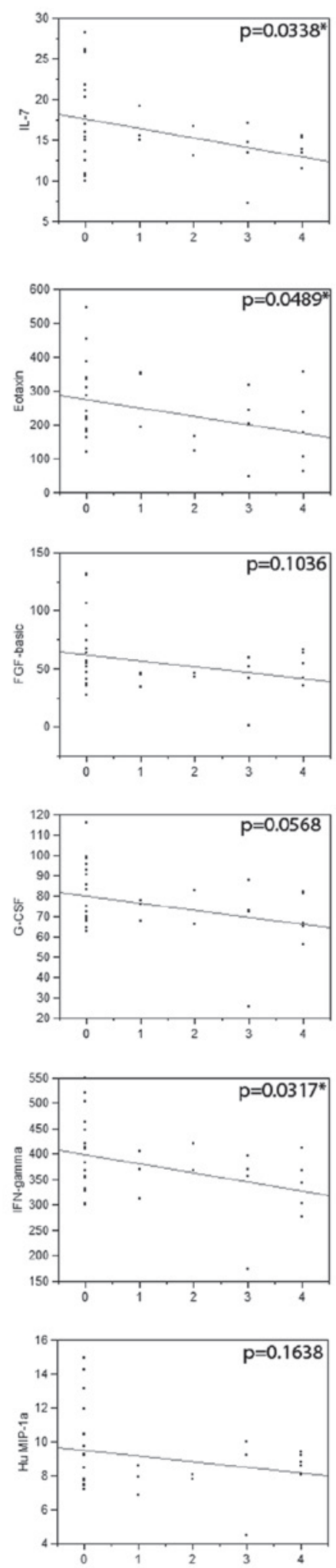

B
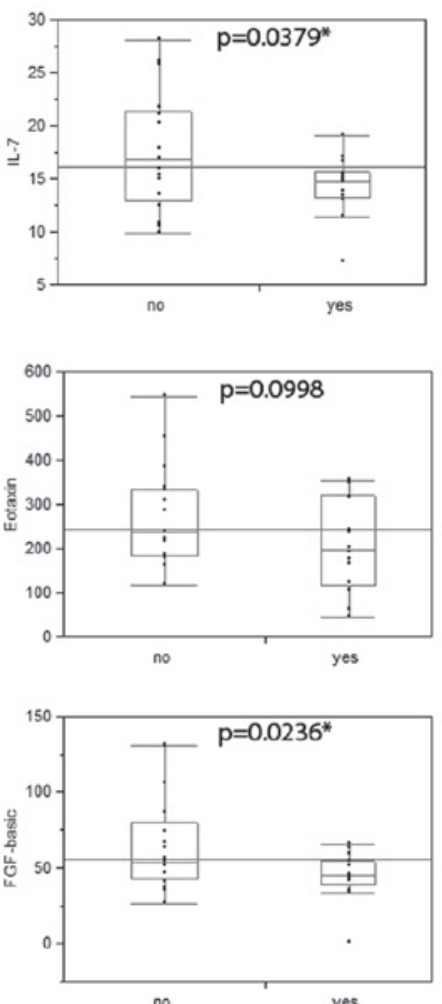

vee
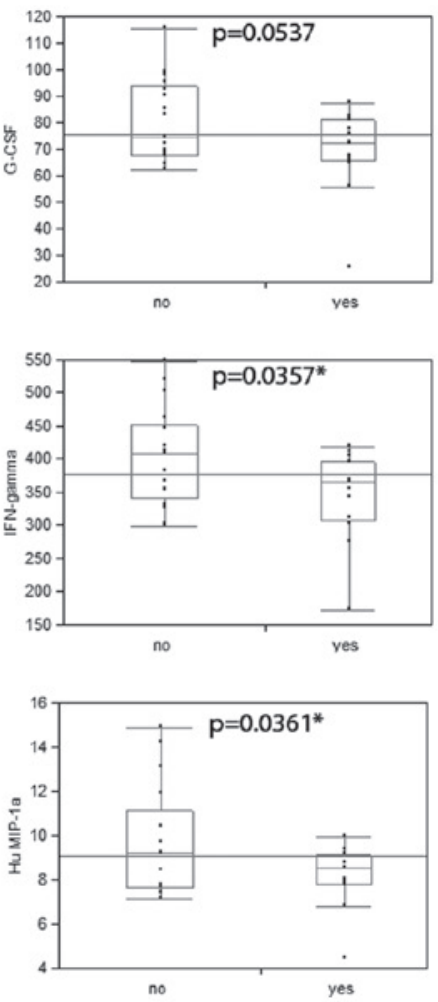

Fig. 3. Cytokine levels that correlated significantly with the numeric N score (on the left) and/or the nodal status (on the right). Statistical significance is indicated by asterisks. 
tion of chemotherapy in head-and-neck cancer patients ${ }^{38}$. Basic fibroblast growth factor expression was associated with good outcomes in patients with squamous cell carcinoma of the oesophagus ${ }^{39}$.

These data might suggest that HNSCC development induces a non-specific immune response, along with increased serum levels of many cytokines, but tumour cells tend to overcome such responses by selectively downregulating specific interleukins, thus promoting tumour progression, particularly lymphatic spreading. This phenomenon would be part of tumour-mediated immunosuppressive activity that, according to several authors, is associated with immune escape, rapid growth and frequent metastasis also observed in other cancers ${ }^{811} 15$.

\section{Conclusions}

Regardless of the molecular/immunological basis of the findings of the present study, from a clinical point of view, the specific alterations associated with regional metastasis are very interesting for several reasons. The most immediate perspective is that downregulation of the above-cited cytokines, and IFN- $\gamma$ in particular, could be used as risk markers of neck metastasis and could serve to modify the therapeutic recommendations by indicating, for example, elective neck treatment in $\mathrm{cN} 0$ cases and comprehensive neck dissection followed by adjuvant radiochemotherapy in $\mathrm{pN}+$ cases. The prognostic role of IFN- $\gamma$ could also facilitate prognostic assessments. Notwithstanding, further studies are necessary to confirm these findings on larger series and to determine the optimal cut-off value of serum IFN- $\gamma$ for risk prediction in clinical practice.

Moreover, the suppression of IFN- $\gamma$ and other cytokines, which we hypothesised to be tumour-dependent and to promote nodal metastasis, could be hindered pharmacologically in attempted immunotherapy for HNSCC, as previously proposed for other malignancies ${ }^{40}$.

\section{References}

1 Siegel RL, Miller KD, Jemal A. Cancer statistics, 2015. CA Cancer J Clin 2015;65:5-29.

2 Ferlay J, Steliarova-Foucher E, Lortet-Tieulent J, et al. Cancer incidence and mortality patterns in Europe: estimates for 40 countries in 2012. Eur J Cancer 2013;49:1374-1403.

3 Shah JP, Patel KJ. Head and Neck Surgery and Oncology. $3^{\text {rd }}$ Edition: Mosby Ltd.; 2003.

4 Ferlay J, Parkin DM, Steliarova-Foucher E. Estimates of cancer incidence and mortality in Europe in 2008. Eur J Cancer 2010;46:765-81.

5 Licitra L, Bernier J, Cvitkovic E, et al. Cancer of the nasopharynx. Crit Rev Oncol Hematol 2003;45:199-213.
6 Gillison ML, Koch WM, Capone RB, et al. Evidence for a causal association between human papillomavirus and a subset of head and neck cancers. J Natl Cancer Inst 2000;92:709-20.

7 Almadori G, Bussu F, Paludetti G. Should there be more molecular staging of head and neck cancer to improve the choice of treatments and thereby improve survival? Curr Opin Otolaryngol Head Neck Surg 2008;16:117-26.

8 Coussens LM, Werb Z. Inflammation and cancer. Nature 2002;420:860-7.

9 Shacter E, Weitzman SA. Chronic inflammation and cancer. Oncology (Williston Park) 2002;16:217-26, 229.

10 Hussain SP, Hofseth LJ, Harris CC. Radical causes of cancer. Nat Rev Cancer 2003;3:276-85.

11 Dobrovolskaia MA, Kozlov SV. Inflammation and cancer: when NF-kappaB amalgamates the perilous partnership. Curr Cancer Drug Targets 2005;5:325-44.

12 Chen Z, Malhotra PS, Thomas GR, et al. Expression of proinflammatory and proangiogenic cytokines in patients with head and neck cancer. Clin Cancer Res 1999;5:1369-79.

13 Douglas WG, Tracy E, Tan D, et al. Development of head and neck squamous cell carcinoma is associated with altered cytokine responsiveness. Mol. Cancer Res 2004;2:585-93.

14 Myers JN, Yasumura S, Suminami Y, et al. Growth stimulation of human head and neck squamous cell carcinoma cell lines by interleukin 4. Clin Cancer Res 1996;2:127-35.

15 Lin WW, Karin M. A cytokine-mediated link between innate immunity, inflammation, and cancer. J Clin Invest 2007; 117:1175-83.

16 Balkwill F, Charles KA, Mantovani A. Smoldering and polarized inflammation in the initiation and promotion of malignant disease. Cancer Cell 2005;7:211-7.

17 Ben-Baruch A. Inflammation-associated immune suppression in cancer: the roles played by cytokines, chemokines and additional mediators. Semin Cancer Biol 2006;16:38-52.

18 Smyth MJ, Cretney E, Kershaw MH, et al. Cytokines in cancer immunity and immunotherapy. Immunol Rev 2004;202:275-93.

19 Duffy SA, Taylor JM, Terrell JE, et al. Interleukin-6 predicts recurrence and survival among head and neck cancer patients. Cancer 2008;113:750-7.

20 Teknos TN, Islam M, Arenberg DA, et al. The effect of tetrathiomolybdate on cytokine expression, angiogenesis, and tumor growth in squamous cell carcinoma of the head and neck. Arch Otolaryngol Head Neck Surg 2005;131:204-11.

21 Riedel F, Zaiss I, Herzog D, et al. Serum levels of interleukin-6 in patients with primary head and neck squamous cell carcinoma. Anticancer Res 2005;25:2761-5.

22 Woods KV, El-Naggar A, Clayman GL, et al. Variable expression of cytokines in human head and neck squamous cell carcinoma cell lines and consistent expression in surgical specimens. Cancer Res 1998;58:3132-41.

23 Tanner J, Tosato G. Impairment of natural killer functions by 
interleukin 6 increases lymphoblastoid cell tumorigenicity in athymic mice. J Clin Invest 1991;88:239-47.

24 Sriuranpong V, Park JI, Amornphimoltham P, et al. Epidermal growth factor receptor-independent constitutive activation of STAT3 in head and neck squamous cell carcinoma is mediated by the autocrine/paracrine stimulation of the interleukin 6/gp130 cytokine system. Cancer Res 2003;63:2948-56.

25 De Schutter H, Landuyt W, Verbeken E, et al. The prognostic value of the hypoxia markers CA IX and GLUT 1 and the cytokines VEGF and IL 6 in head and neck squamous cell carcinoma treated by radiotherapy +/- chemotherapy. BMC Cancer 2005;5:42.

26 Casasnovas RO, Mounier N, Brice P, et al. Plasma cytokine and soluble receptor signature predicts outcome of patients with classical Hodgkin's lymphoma: a study from the Groupe d'Etude des Lymphomes de l'Adulte. J Clin Oncol 2007;25:1732-40.

27 Westin U, Nystrom M, Ljungcrantz I, et al. The presence of elafin, SLPI, IL1-RA and STNFalpha RI in head and neck squamous cell carcinomas and their relation to the degree of tumour differentiation. Mediators Inflamm 2002;11:7-12.

28 Neville LF, Mathiak G, Bagasra O. The immunobiology of interferon-gamma inducible protein $10 \mathrm{kD}$ (IP-10): a novel, pleiotropic member of the $C-X-C$ chemokine superfamily. Cytokine Growth Factor Rev 1997;8:207-19.

29 Monteagudo C, Martin JM, Jorda E, et al. CXCR3 chemokine receptor immunoreactivity in primary cutaneous malignant melanoma: correlation with clinicopathological prognostic factors. J Clin Pathol 2007;60:596-9.

30 Furuya M, Suyama T, Usui H, et al. Up-regulation of CXC chemokines and their receptors: implications for proinflammatory microenvironments of ovarian carcinomas and endometriosis. Hum Pathol 2007;38:1676-87.
31 Pellegrino A, Antonaci F, Russo F, et al. CXCR3-binding chemokines in multiple myeloma. Cancer Lett 2004;207:221-7.

32 Jones D, Benjamin RJ, Shahsafaei A, et al. The chemokine receptor $C X C R 3$ is expressed in a subset of B-cell lymphomas and is a marker of B-cell chronic lymphocytic leukemia. Blood 2000;95:627-32.

33 Lo BK, Yu M, Zloty D, et al. CXCR3/ligands are significantly involved in the tumorigenesis of basal cell carcinomas. Am J Pathol 2010;176:2435-46.

34 Koch T, Eiffert H, Spindler MB. Relevance of the new tumor marker SCC (squamous cell carcinoma antigen) for the diagnosis and follow-up control of squamous epithelial carcinoma of the head and neck. HNO 1989;37:454-59.

35 Sheu BC, Lin RH, Lien HC, et al. Predominant Th2/Tc2 polarity of tumor-infiltrating lymphocytes in human cervical cancer. J Immunol 2001;167:2972-8.

36 Katayama A, Ogino T, Bandoh N, et al. Expression of CXCR4 and its down-regulation by IFN-gamma in head and neck squamous cell carcinoma. Clin. Cancer Res 2005;11:2937-46.

37 Caserta S, Alessi P, Basso V, et al. IL-7 is superior to IL-2 for ex vivo expansion of tumour-specific CD4(+) T cells. Eur $\mathrm{J}$ Immunol 2010;40:470-9.

38 Argiris A, Lee SC, Feinstein T, et al. Serum biomarkers as potential predictors of antitumor activity of cetuximab-containing therapy for locally advanced head and neck cancer. Oral Oncol 2011;47:961-6.

39 Nakamura T, Ozawa S, Kitagawa Y, et al. Expression of basic fibroblast growth factor is associated with a good outcome in patients with squamous cell carcinoma of the esophagus. Oncol Rep 2005;14:617-23.

40 Sgambato A, Cittadini A. Inflammation and cancer: a multifaceted link. Eur Rev Med Pharmacol Sci 2010;14:263-8. 